\title{
SEVILLA, BIORREGIÓN Y EQUIDAD SOCIAL: GOBERNAR EN FUNCIONES
}

\author{
Editor Carlos TAPIA \\ Departamento de Historia, Teoría y Composición Arquitectónicas. Universidad de Sevilla \\ https://dx.doi.org/10.12795/astragalo.2019.i26.01
}

El mundo está en funciones. Por definición, se ejerce el gobierno en sustitución de quien le corresponde ejercerlo en propiedad. Puede tratarse de una extensión de los gobernantes previos al cese, pero siempre con una limitación de acción, una incapacidad.

En el momento de escribir esta editorial para el número 26 de la revista Astrágalo, legalmente está en funciones el gobierno español, muchas de sus Comunidades Autónomas, el gobierno británico (con un Brexit también en funciones como resultado una incompetencia-carencia de capacidad-generalizada), o el Consejo de la Unión Europea. En estos días, los líderes de estos territorios, pero también de los que ejercen con toda la capacitación legal, parecen actuar como si no contaran con la confianza de las Cámaras Legislativas. No se trata de no poder proponer o aprobar leyes, a pesar de ser ésa la limitación legal, sino de mostrar ante los ciudadanos una sobreactuación de tintes grandilocuentes, renovadores, con clara consciencia de la imposibilidad de su cumplimiento. Se trataría del paso siguiente a la promesa electoral resignificada después del resultado electoral. Antes del 2 de Julio 2019, los altos cargos europeos deben ser elegidos y sus prioridades para el periodo 2019-2024 desplegadas.

Este tiempo inoperativo, en funciones, no parece ser relativo a una transición necesaria, sino síntoma de un estado final, para el que no hay objetivos. Latour (“¿Dónde aterrizar?”) ha dejado despejada la duda de la inacción por sobreactuación al citar en primera página al yerno de Trump con su sentencia "ya hemos leído suficientes libros". Si se trataba de pasar a la acción, desde luego no es con conciencia de comunidad, sino de saberse en el lugar justo el día final para salvar su forma de vida, dado que es imposible un cambio en el rumbo de co- 
lisión. Ya no es (ya no hay) tiempo de restañar inequidades y sí de paradójicas reafirmaciones identitarias. Sin embargo, aquella división en la que los fascismos se ratifican en una idea sobre la esencia de la comunidad, y los comunismos, sobre la base de una praxis no sustancial, no parecen sino hecha por un conjunto de usuarios de una biblioteca de libros en papel, sin presupuesto para adquisiciones desde 1945. Tampoco sirven la polaridad local/global, ni la oposición en política de la izquierda contra la derecha.

Esos usuarios de carnet plastificado ni tienen una voluntad de pertenencia, ni apuntan sus reflexiones en la dirección certera. Como diría Jean-Luc Nancy, este invento de la comunidad es excrecencia de lo que llamamos "sociedad". Es una trampa (así lo dice en "La comunidad inoperativa" pág. 31) económica, técnica, política, cultural. La comunidad es "lo que nos ocurre" a partir de la sociedad. Y, por ello, Latour diagnostica miopía a cualquiera que conciba tomar decisiones por la vía de la política que no tengan en cuenta la nueva delimitación de los conflictos, que van, según el autor francés, de lo Moderno a lo Terrestre. Se trata de una nueva ecología política ${ }^{1}$ de orientación al objeto, que está encima de la mesa de las principales universidades y entre ellas, de las Escuelas y Facultades de Arquitectura ${ }^{2}$.

Si observamos qué ocurrió en 2015 en la unión europea cuando lanzó sus propuestas

1 Recuérdese aquí el libro "Para una crítica de la ecología política”, de Hans Magnus Enzensberger. Barcelona: Anagrama, 1974. Fue una crítica anticipatoria de que los problemas no están situados sino en el modo de producción. Sin que cambien, no hay solución.

2 Este debate de los realismos especulativos y la Ontología del objeto orientado está llegando y en Astrágalo estamos atentos a su decantación arquitectónica, para la que se prepara un número temático. prioritarias para su mandato, encontramos estas prerrogativas: Empleo, crecimiento e inversión; Mercado único digital; Unión de la Energía y clima; Mercado interior; Una Unión Económica y Monetaria más justa y más profunda; Una política comercial equilibrada y progresiva para encauzar la globalización; Justicia y derechos fundamentales; Migración; Un interlocutor de mayor peso en el escenario mundial; Cambio democrático.

Con estas claves, no se entrevé que haya un estado límite de los últimos días, sino un perfeccionamiento de lo que ya funciona con autonomía, es decir, que no depende de la voluntad de acción de sus dirigentes. Europa se siente cuna y valedor universal de la democracia. Pero se trataría de ver en este lapso de lo que quiso y lo que busca ser, si aquellas prioridades han supuesto cambios efectivos, y si la inacción por "caretakerness" se traslada de la sociedad a las comunidades.

Hay poco más de 2000 km de Bruselas (Bélgica) a Sevilla (España), unas 20 horas de automóvil, casi 17 en tren, y alrededor de 2 horas y media en vuelo por 150 euros. No parecen números insalvables $\mathrm{y}$, sin embargo, ¿qué caracterizaría un reconocimiento de esta ciudad andaluza indiferentemente a lo prioritario europeo, a la falta de objetivos comunes, al saqueo previo a los últimos días?

¿Qué hace la arquitectura para las comunidades que se reflejan en otra idea de sociedad?

¿Puede una ciudad-mundo ser reconocida por acciones que no se recogen en sus anuarios oficiales? ¿Cuánto tiempo duraría una acción disidente fuera de los anuarios? 
Astrágalo 26 busca acciones -y pensar es accionar-, donde Sevilla se presente frente a sí misma desde posicionamientos propios.

En el registro que como editores hemos hecho en los meses de preparación del que será el último número de 2019 y primero de una serie de monográficos sobre ciudades en todo el mundo, una de las exploratorias más interesantes es la de la función de la Equidad. Así se ha reconocido desde observadores exteriores para la propia ciudad de Sevilla, y así querríamos considerar como mirada desenfocada, la que trasluce diferencialmente después de ser la ciudad elegida por la guía Lonely Planet como mejor destino para viajar en 2018, habiendo recibido en ese año más de 3 millones de turistas. En 2019, ha celebrado la Cumbre Mundial del Turismo, con Obama como carísimo invitado, los MTV Europe Music Awards se acogen en la ciudad, por hablar de su internacionalización. Pero también ingresa anualmente unos 4500 millones de euros por los polos industriales del Puerto, Aerópolis -en un progresivo auge- y el parque tecnológico de La Cartuja, siendo en conjunto un cuarto de los ingresos de la capital andaluza. Es la cuarta ciudad española por número de habitantes (688.711), la 19 en renta (23.738 € bruta). Pero, ¿cómo se mide la equidad?

En la lista de prioridades de la Unión Europea para el periodo recientemente finalizado, solo ha sido posible reconocer la noción de equidad, como declarativa, en el epígrafe Una Unión Económica y Monetaria más justa y más profunda. Este apartado se explica con la frase: Combinar estabilidad con equidad y responsabilidad democrática. Si hay equidad, es en el reparto económico, como actitud política, supeditada a la estabilidad general, se advierte, por si alguien olvida que estamos en funciones.
Esta advertencia se inscribe en el propio término elegido. Es decir, no se trata de igualdad, sino de equidad.

En 2017, el diario Le Monde, publicó uno de sus atlas divulgativos pero rigurosos, con el título de "Atlas de Economía Crítica", que incluía el breve texto "equidad: trampantojo de la igualdad". La Igualdad, se explica en el Atlas, establece, desde la declaración francesa de los Derechos del Hombre (humanos decimos hoy, sin conseguir siquiera igualdad en el género con ello) y del Ciudadano, que todos los individuos tienen los mismos derechos y deberes.

Es sabido que cada ciudadano, en esa época, si era tal, debía someterse pacíficamente al nuevo orden social, germinal, obligado con el cumplimiento de derechos y deberes propios del estado de derecho. Recuérdense en este instante dos libros de Rancière ${ }^{3}$ a propósito de la igualdad para la educación en Jean Joseph Jacotot.

Actualmente, como declarativa no es discutida, pero su función dista mucho de haber cumplido en lo que a objetivos se trata. O, dicho de otro modo, si es empleada en el plano político se acepta, pero es inaceptable su corto alcance en el plano social desde la Revolución Francesa hasta nuestros días. Lo cual lleva a pensar la interinidad del gobernante que marca su agenda con lo político, dado que no hay acción que lo traslade a la sociedad (y, por tanto, a las comunidades, atrapadas por sus propios designios). Si igualdad en el nivel político podría definirse como ideología política para los bienes comunes regidos por leyes, equidad, en el social, sería un tipo de "discriminación positiva" a favor del reconocimiento de las diferencias. Una percepción ampliada de ello quedaría allanada

3 El maestro ignorante. Cinco lecciones para la emancipación intelectual (2003) y El espectador emancipado (2010) 
si decimos que no es posible la igualdad sin que haya -previamente- inequidad. Pero que al saber que nada impide al capitalismo mantener su orden, o somos injustos para mejorar a los desfavorecidos, o no habrá mejora alguna. Es una contradicción in termini cuya articulación conllevaría ir más allá de la mera mejora económica, con lo que cabría buscarla obligadamente en más epígrafes prioritarios en Europa en el periodo anterior y en el que está a seguir.

¿Qué queremos decir con Equidad? Equidad se compone de varios principios, a modo de constitución, que establecerían una carta magna básica, que en el territorio de la ciudad podría tener un título para su mandato: Ecología Política Urbana (UPE según Swyngedouw). Pero debería liberarse de tu manifestación por lo urbano, alcanzando un enraizamiento territorial más acorde al planteamiento de naturaleza y sociedad entrelazados como única entidad. Tal vez se pudiera apostar por el de biorregión. En una biorregión, el metabolismo urbano no establece que factores vitales (agua, energía, comida, etc.) se conviertan en mercancía para su manipulación por parte de mano de obra especializada y alto beneficio para unos pocos. Una Ecología Política Biorregional tendría 4 principios: Justicia Ambiental, Lo Común, Los sentidos de pertenencia y Los Derechos (a la ciudad, al paisaje, a la inclusividad, a la dignidad, etc.).

Por Justicia Ambiental, desglosaríamos 4 aspectos esenciales (según Iris Marion en 1990 y David Schlosberg en 2007): una Justicia Distribucional (que sería la necesidad de que los males ambientales no se concentren en o cerca de las comunidades desfavorecidas sino (re) distribuidos más equitativamente), una Justicia Procedimental (la necesidad de un proceso de toma de decisiones más justo y democrático y la participación de los grupos desfavorecidos en él), una Justicia de Capacidades (la necesidad de crear 'las capacidades necesarias para una comunidad saludable y funcional') y una Justicia de Reconocimientos (la necesidad de reconocimiento y respeto por las comunidades desfavorecidas que sufren de injusticia ambiental y por quienes participan de su lucha).

Para dimensionar sus potencialidades se articulan operadores, que serían, entre otros, la Cohesión y el Tejido Social, la Movilidad, la Gobernanza o la Riqueza (nótese que no está más arriba la riqueza situada, sino en la forma en que el trabajo o la economía se integran en la sociedad para fines muy distintos a los que hasta ahora se han tenido en consideración, como la división del trabajo que promueve inequidad por definición, y que Lefebvre ensamblaría diferentemente con la acción arquitectónica en la necesidad de "une architecture de la jouissance").

Por su parte, el uso del término "lo Común" o "los Bienes Comunes", se refiere a un cambio de mentalidad, más que a grandes ideas renovadas, pero que luchan por desapropiar los sentidos atribuidos a nociones básicas, aparentemente inamovibles, que conforman las sociedades, como ha escrito David Bollier en el capítulo titulado "The Growth of the Commons Paradigm" (MIT 2007). Reorganizar las directrices del llamado "Dominio Público Global" es su función. El arquetipo de los bienes comunes no se basa principalmente en un sistema de propiedad, contratos y mercados, sino en reglas y normas sociales, además de en mecanismos legales que permiten a las personas compartir la propiedad y el control de los recursos. "The tragedy of the Commons", escrito por Garrett Hardin, en la década de 1960, y citado por el ahora famoso autor Yochai Benkler a principios 
de la década de 2000 en su conferencia sobre la política económica de los bienes comunes, junto a la publicación del libro de 1990 de Elinor Ostrom, "Governing the Commons" es la principal línea genealógica sobre este asunto enormemente desarrollado hasta nuestros días, y tenido como clave política en la Europa actual. Aquí son cruciales los operadores como Espacio Público, Patrimonio, Servicios, o el Conocimiento. Nancy Fraser (UNAM, 2003) ha escrito, basándose en Foucault, que, si la regulación fordista aspiraba a la universalidad a pesar de su persistente desigualdad, la gubernamentalidad postfordista por su parte separa y canaliza a los individuos según su grado de eficiencia y de la previsión de riesgos, enunciándose una "sociedad dual" de hiperconectados y excluidos. Pensar lo Común, doblega, o al menos, lo pretende, el vector de la inequidad por contrapeso.

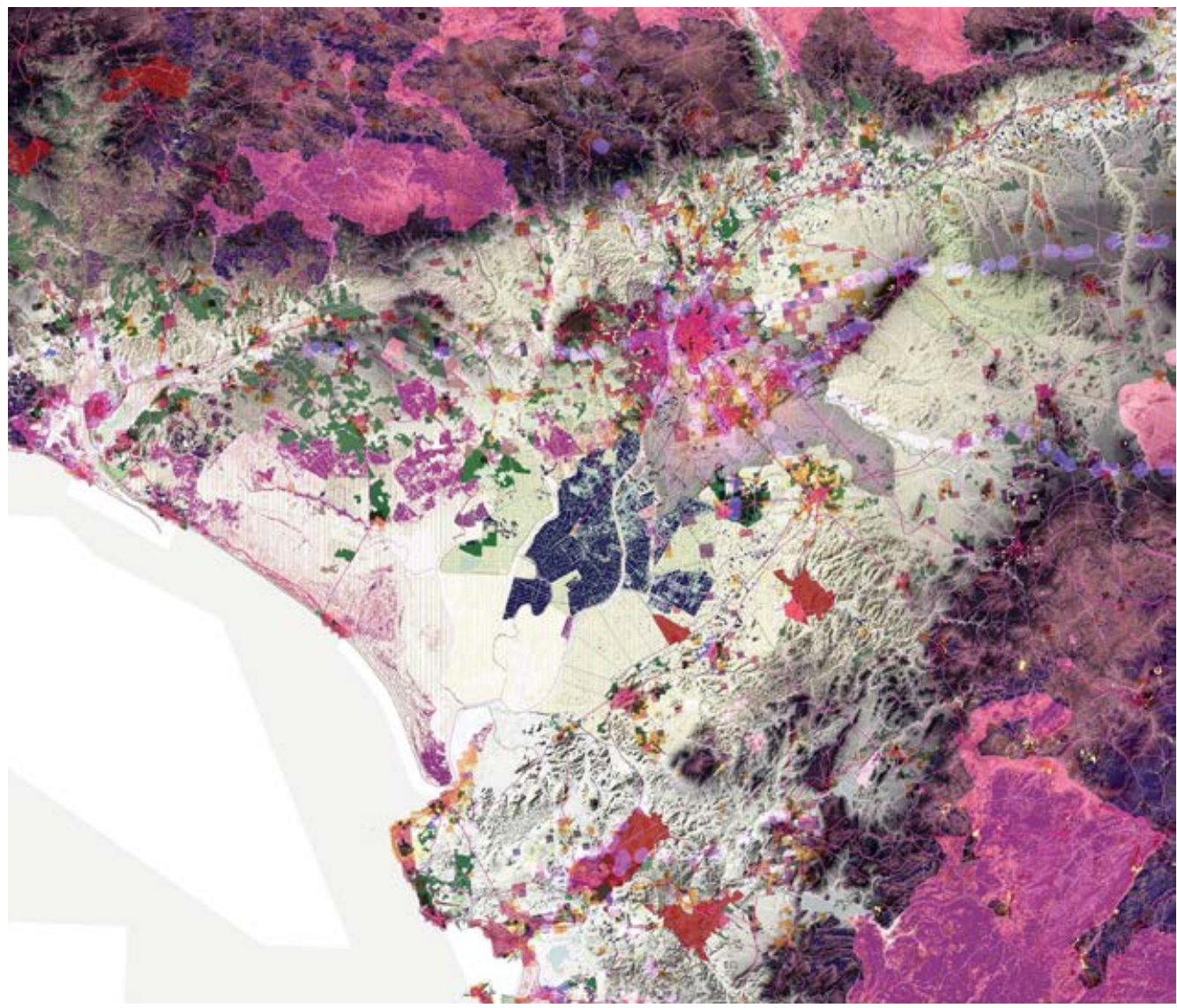

Fig. 1. Sevilla y su estructura territorial. Imagen desarrollada con datos open source por TELL-me Seville Team, 2019 (Domingo Sánchez, Blanca del Espino, Emilio Mascort, Carlos Tapia, junto con Valentina Galiulo). Training for Education, Learning and Leadership. Towards a new MEtropolitan discipline TELL-me. KEY ACTION: 2 - Cooperation for innovation and the exchange of good practices. Strategic Partnership.

Erasmus Plus. European Union. Institution at charge: Politecnico di Milano- DAStU'- MSLab Fondazione 'Politecnico di Milano'. 
Sobre los sentidos de pertenencia, autodenominación o conciencia colectiva, cabe decir que las comunidades no responden a las regulaciones y proyectos situados sobre delimitaciones tradicionales (municipales, de distrito, etc.), sino que se abren nuevas territorialidades en los antiguos límites, ahora áreas de confluencia. Pueden ir desde la emergencia de nuevas áreas metropolitanas, los procesos en la llamada post-metropoli, las comunidades en transición, etc. Sus operadores serían el ensamblaje de lo humano con lo no humano, la centralidad, la resiliencia de las comunidades, etc.

Por último, los Derechos. De todos es conocida la investigación realizada por Lefebvre a finales de los años sesenta, con el nombre de "el derecho a la ciudad". Entendida en su origen, debe considerarse como una postulación entusiasta de un tipo nuevo y radical de política urbana. En la actualidad, es difícil recomponer ya ese origen, aunque es habitual intentar invocarlo inalterado en contextos más reformistas. Fue Harvey, en su ensayo de 2008 "El derecho a la ciudad", quien rearticuló la creencia central de Lefebvre, argumentando que "el derecho a la ciudad es mucho más que la libertad individual para acceder a los recursos urbanos: es un derecho a cambiarnos a nosotros mismos cambiando la ciudad". A pesar de la desconfianza de Lefebvre por dar cabida a los arquitectos en esta política urbana, desde la arquitectura hemos creído encontrar una solución para dar a todos los ciudadanos una porción de equidad basada en nuestro hacer para lograr la participación y apropiación del espacio público por los habitantes.

Astrágalo 26, focalizado en los procesos de equidad que se pueden registrar en la ciudad española de Sevilla, no pretende extender un "principio de esperanza" en el sentido de Ernst Bloch, ni siquiera en el de responsabilidad por el de Jauss, no tiene una posse altermundista. Intenta localizar prácticas que se basen en los 4 principios definidos para la equidad conviviendo en la orfandad de gobiernos interinos. Con ello, se pretende comprender la cotidianidad de una inteligencia arquitectónica en gestación, junto con otras prácticas sociales. A tal reunión podría llamársele biorregión, desdibujando los límites impuestos por una ciudad en alza económica y de representatividad.

Este número comienza con el artículo del urbanista Pedro Górgolas quien sitúa a la ciudad de Sevilla, históricamente, en una relación distante con su entorno metropolitano. Las iniciativas emprendidas para proceder a configurar una estructura territorial congruente, bien articulada, policéntrica y ambientalmente cualificada, han terminado, como él indica, abocadas a la irrelevancia. Esta frustrante trayectoria fue invertida, ya entrado el siglo XXI, gracias a la confección de un instrumento de planificación de alcance supramunicipal -el Plan de Ordenación del Territorio de la Aglomeración Urbana del año 2009- que ha contado con el suficiente consenso interadministrativo. Sin embargo, paradójicamente, se ha preservado la autonomía de decisión de los diferentes ayuntamientos para idear sus propios modelos urbano-territoriales. Ello ha devenido la aceptación de la expansividad territorial promovida por el planeamiento municipal vigente, gestado, en su mayor parte, durante la última burbuja inmobiliaria. Pero, además, el Plan Subregional ha incrementado irracionalmente el suelo urbanizable existente, las denominadas Áreas de Oportunidad Supramunicipal. Esta decisión, que subvierte el modelo de ciudad com- 
pacta preceptuado en el Plan de Ordenación del Territorio de Andalucía, revela su adscripción por prorrogar los protocolos operacionales del urbanismo neoliberal que caracterizó el frenesí urbanizador de la llamada "década prodigiosa" en España (1997-2007). El artículo de Górgolas es una puesta en claro, que tan urgente era que fuera desvelada, de lo que tenemos hoy como resultado de décadas de planeamiento en el área metropolitana de Sevilla y sus entornos.

Este preámbulo tiene su expansión en dos textos que introducen al concepto de biorregión. El primero, del geógrafo Juan Requejo, expresa que la ciudad de Sevilla, como todas, responde a tres funciones básicas: proveer de bienestar a sus habitantes, dar soporte a sus medios de vida y cuidar de la salud ecológica del territorio. Para satisfacer sus funciones, debe sustentarse en un metabolismo adecuado y garantista. La visión mecánica, propia de la Modernidad, ha conseguido dar respuesta a las dos primeras funciones recurriendo a un elevado consumo de materiales y energía, a costa del cuidado de la salud ecológica del territorio, que está muy abandonado. Para Requejo, el reto actual de la descarbonización debe adoptar un planteamiento radicalmente distinto, un enfoque biorregional basado en el funcionamiento orgánico y en la autorregulación.

En segundo lugar, siguiendo con biorregión, la geógrafa Águeda Villa, reflexiona sobre tal concepto indicando que con él se persigue ensayar fórmulas de análisis y gestión socioterritorial, sustituyendo la lógica dualista naturaleza-cultura por el entendimiento de que los procesos naturales y humanos van siempre unidos. Desde este prisma y para una buena compresión e interpretación del hecho urbano, mantiene como hipótesis que es importante flexibilizar los límites. En el caso de Sevilla, su artículo propone desdibujar sus límites hasta el océano Atlántico, intentando mostrar que la triada ciudad-río-marismas puede relacionarse entrelazando su destino físico natural, histórico, cultural y social.

A partir de aquí, los artículos que siguen muestran desde distintos escenarios biorregionales las capacidades de enfoque que darían una comprensión para propios y extraños de lo que Sevilla puede significar en la ampliación de sus sentidos: recorrer desde los convencionales y muy arraigados, y hacia los especulativos, no menos pregnantes. Así, los profesores de Proyectos Arquitectónicos de la Escuela de Arquitectura de Sevilla José López-Canti y Félix de la Iglesia, imparten docencia diagnosticando tiempos y espacios locales como derivas, intuiciones, cambiando los márgenes de la Sevilla urbana para situarlos, más allá, en su corona metropolitana, rica en ámbitos distinguidos tanto por su valor medioambiental como por las dinámicas de ocupación de suelo. La expansión urbana generó unos modos de vida que hoy no encuentran su sentido pleno en su condición periférica y sí podrían reconfigurarse bajo lo que ellos llaman el "prisma de la agr-y-cultura", sustituyendo una consabida mirada urbana por la agroecológica, ligada indisolublemente a las pequeñas comunidades conscientes de las oportunidades de vida si se prima la integración de personas y bio-territorios ampliados o "de los confines".

En una escala de intervención intraurbana, la arquitecta Reyes Gallegos muestra un proyecto singular, de entre los que la ciudad declara como experimentales. Gallegos entiende la ciudad como organismo vivo, y en el caso 
de Sevilla, requiere respuestas que inviertan la dinámica urbanizadora de las últimas décadas, -como narra perfectamente Górgolas- para que regeneren, oxigenen y devuelvan el ciclo natural a la tierra. Su apuesta de equidad urbana consiste en "sustituir lo funcional por lo metabólico, lo productivo por lo reproductivo; el capital por la vida".

Es evidente que son posibles lecturas diferentes de la ciudad y su biorregión, a depender de quienes escriban, de sus orientaciones, del enfoque editorial. No obstante, debe entenderse que este número de Astrágalo ha querido invitar y reflexionar desde una óptica no habitual, no convencional. El resultado creemos que es muy valioso para el debate interno, $y$ como metodología de aproximación para otras ciudades. Para reflejar los deseos de gobernanza y la comprensión de los comunes en la organización supraurbana, hemos invitado a la Asociación ADTA que, con clara consciencia de su necesidad de existencia, de su compromiso con su existencia, diríamos mejor, estudian y proponen actuaciones a los lugares asociados a las segundas y terceras periferias de nuestras grandes ciudades, de Sevilla en concreto. Aquí, el encuentro entre el medio rural y urbano, con sus distintos modos de vida, se hace más difuso y comprometido. Más comprometido porque el rural-urban linkage es de especial transcendencia: despoblamiento en el medio agrario, banalización e inequidad en las bolsas residenciales extensivas del área metropolitana.

Para desarrollar lo que anteriormente nombrábamos como los sentidos de pertenencia, hemos invitado al filósofo Isidoro Reguera a explorar (literalmente) eso que identifica al sevillano con su modo de vida: los bares. Con la expresión “4000 bares de presión”, se diría que ese número real de establecimientos marca la presencia del habitante de esta ciudad en sus calles y en esos lugares. No se entiende ni Sevilla ni a los sevillanos, sin ellos. Pero no es un ritual cualquiera ni son sitios de moda, esos lugares. No se es barero ni se es bar por consumir o por ocupar un lugar. El magistral recorrido que Reguera muestra, acomodando tono y reflexión a lo que solo el que pertenece sabe destacar, será uno de los artículos más singulares que el reconocido catedrático, escritor y traductor haya redactado en relación con la espacialidad de la arquitectura.

¿Se podría definir una ciudad con un cuerpo que la danza? Sin duda. Y así lo muestra el trabajo de la coreógrafa Manuela Nogales, que pone de relieve la reflexión conjunta que hace con la arquitecta y especialista en danza María Aguilar. En un sensitivo ejercicio de percepción conjunta, de constitución de un cuerpo común más allá del propio cuerpo, este artículo da respuesta a un nuevo cambio de escala en la definición de la ciudad ampliada de Sevilla. La común agitación permanente del cuerpo y lo urbano, como ellas destacan del sociólogo Manuel Delgado, entra en resonancia cuando la danza contemporánea se encarga de desvelar lo que de otra manera no cabe vislumbrar.

Se cierra el número con un artículo de la arquitecta y editora Paula V. Álvarez sobre bienes comunes, equidad e iniciativas sociales. En ese texto se estudia la puesta en funcionamiento de la Red de Moneda Social Puma (RMSP). Es una red de moneda social local (1 puma = 1 euro) diseñada por un grupo de 30 personas que se inició con más de 800 usuarios en el año 2012 en la ciudad de Sevilla y fue cerrada en diciembre de 2019.

Surgida para ayudar a colectivos vulnerables afectados por las crisis económicas 
tras el estallido de la burbuja inmobiliaria en 2008, es un dispositivo de cuidado mutuo, de reivindicación del derecho a la ciudad, ligado a las prácticas experimentales urbanas que reconfiguran el paisaje urbano del casco histórico norte de Sevilla, presionado desde mediados de la década de los 90 por las dinámicas de gentrificación. Está vinculada a un nuevo tipo de territorio, que emerge dentro del paisaje urbano, con un papel activo en la creación de un tejido económico alternativo, que es también político, cultural y simbólico. La RMSP no puede entenderse separada del contexto geográfico e histórico en el que surge ni del contexto social y cultural en el que opera. Lo que la singulariza, según Álvarez, es que incorporó con cautela trazas y fragmentos de la realidad que se deseaba transformar, facilitando así que nuevos valores penetrasen en las instituciones formales y contribuyendo de esta manera a ampliar el alcance de una re-imaginación del valor en curso. La RMSP hoy puede ser pensada en relación con los conflictos vivos del presente, en especial los dispositivos de cuidados mutuo que se están poniendo en los centros sociales auto-gestionados tras la crisis originada por el evento COVID-19.

Por diversas razones, este número se ha atrasado en su publicación seis meses. Entre las razones, se debe mencionar la aparición del virus SARS-CoV-2, que obligó a algunos autores a reinventar su trabajo además de su vida. Por ello, algunos artículos mencionan el efecto de la pandemia y otros, entregados antes, no. A pesar de esta demora en la publicación, con casi un año desde que se gestó el editorial para este número, resulta a nuestros ojos esa distancia del mayor interés. La expansión del virus pasa por Sevilla en el momento del cierre del número con una desescalada del confinamiento, de una cierta relajación en el rigor del distanciamiento social. América Latina ya es el principal foco de concentración pandémico. Pero aquí, en Europa, los gobiernos siguen en una cierta interinidad, asociada a que sus decisiones se toman por comités delegados: al principio por expertos en salud, al final por expertos en economía, como denuncia como lamento el propio Latour con la presidencia de Macron. No es muy diferente en España. La nueva normalidad conduce a la salvaguarda de los mismos, con los recortes a los demás, la inmensa mayoría. La Unión Europea ha demostrado durante la pandemia que no está tan unida.

En este escenario, cuya representación alegórica de la realidad no tiene programada una finalización, su teatralidad es la misma realidad. Por ello son tan precisas las difusas imágenes del artista visual Jorge Yeregui. La suma de sus apariciones repartidas por el número debe considerarse como un artículo visual. Cumple con todo lo que los demás artículos muestran: una sustancialidad argumental, una línea de coherencia crítica y una creatividad singular. La expulsión del ciudadano tras ser convidado a participar de un sueño colectivo de ciudad, es patente en la reiteración en cada imagen por el blindaje de los deseos tras el espesor de las vallas, de las materialidades y texturas de las composiciones de querencia de cotidianeidad, inversamente hápticas, inversamente insertas en la bio-territorialidad y la equidad social. 


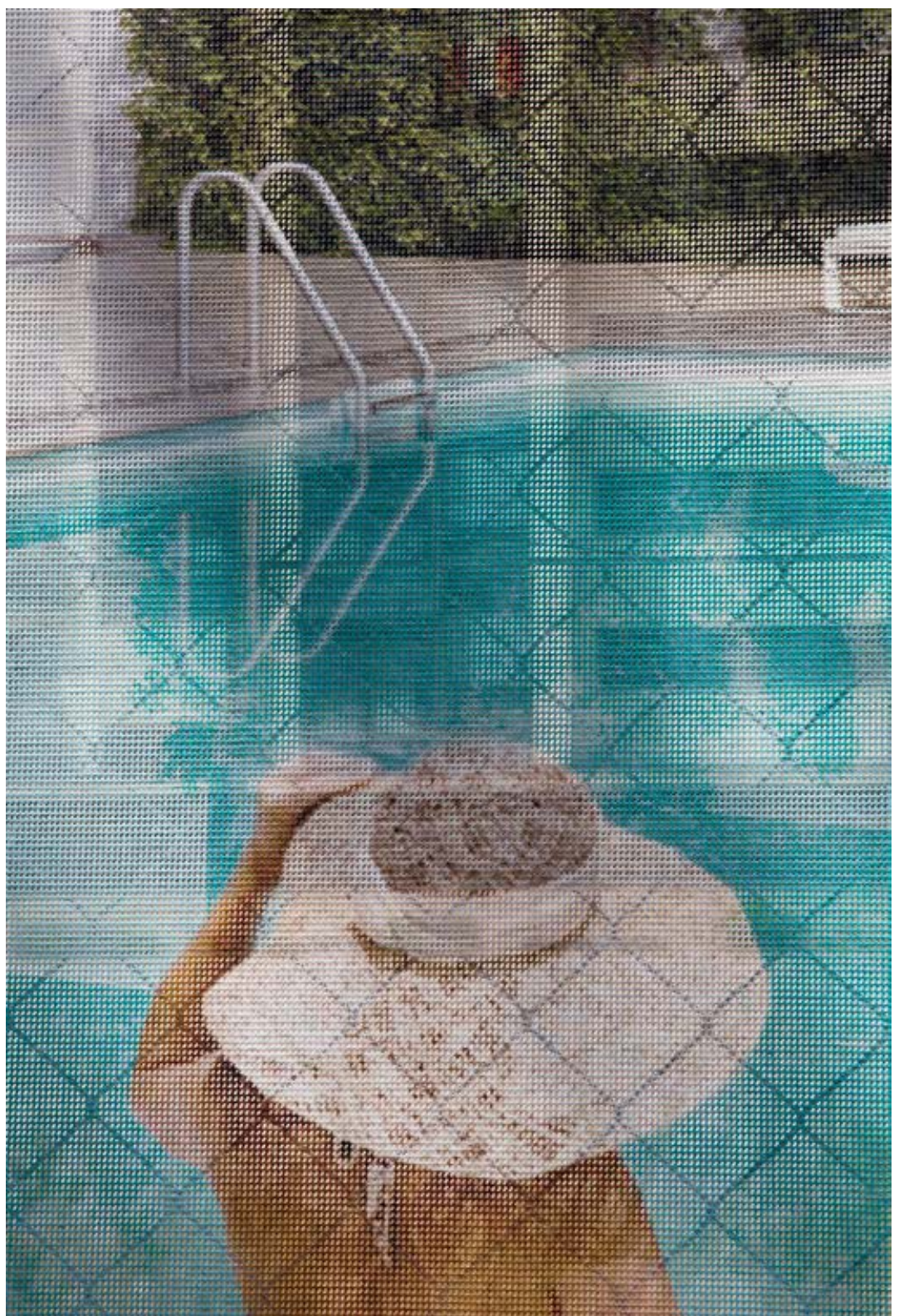

